Journal of Case Reports 2017;7(4):400-403

\title{
An Unusual Case of Low Transverse Vaginal Septum
}

\author{
Chetana Ratnaparkhi ${ }^{1}$, Nakul Gawade ${ }^{1}$, Avinash Dhok ${ }^{1}$, Anuja Bhalerao ${ }^{2}$, Vikrant Bhende ${ }^{1}$ \\ Departments of ${ }^{1}$ Radiodiagnosis and ${ }^{2}$ Obstetrics and Gynaecology, NKP Salve Institute of Medical Science and Lata \\ Mangeshkar Hospital, Hingna Road, Nagpur, 440019. Maharashtra, India.
}

\section{Corresponding Author:}

Dr. Nakul Gawade

Email: nakulgawade07@gmail.com

This is an Open Access article distributed under the terms of the Creative Commons Attribution License (creativecommons.org/ licenses/by/3.0).

Received : December 12, 2016

Accepted : November 27, 2017

Published : December 20, 2017

\begin{abstract}
Background: The complete or imperforate transverse vaginal septum is a rare anomaly of the female reproductive tract. Its site varies in the vaginal canal. The common sites are upper and middle third of the vagina, the low transverse vaginal septum is very rare. It is found in association with urological anomalies and anorectal malformation as well as other Mullerian anomalies especially bicornuate uterus. Case Report: We report a case of a 13-year-old girl with hematometra, hematocolpos and hematosalpinx due to an imperforate complete low vaginal septum. Conclusion: Hematosalpinx presence adversely affects the fertility and obstetric outcomes in the patient. MRI is important diagnostic modality that helps in deciding the management and so as predicting future outcome.
\end{abstract}

Keywords: Transverse Vaginal Septum, Hematometra, Hematocolpos, Hematosalpinx, Magnetic Resonance Imaging.

\section{Introduction}

Transverse vaginal septum is a vertical fusion defect of the Mullerian ducts that develops due to failure of resorption of the tissue between the vaginal plate, originating from the urogenital sinus and the caudal aspect of the fused Mullerian ducts. Normally this resorption occurs around the fifth month of gestation. The prevalence of transverse vaginal septum is reported to be 1 in 30,000 to 1 in 84,000 [1] and it was first described by Delaunay in 1877 [2].

A transverse vaginal septum results in reduced functional length and in most situations outlet tract obstruction resulting in hematometra and hematocolpos and rarely hematosalpinx. Upper vaginal septa are most common (46\% of cases) followed by the mid (40\% of cases) or lower (14\% of cases) vagina [3].

MRI is important in diagnosing the complications like hematometra, hematocolpos and hematosalpinx more accurately than any other imaging modality and helps in deciding the management and predicting future outcome. Introduction of ultrasound jelly in the introitus better delineates transverse vaginal septum and jelly itself serves as a contrast. Here we present the case of complete or imperforate transverse vaginal septum which is a rare anomaly of the female reproductive tract.

\section{Case Report}

A 13 year old pre-menarchial girl presented to the emergency department with history of episodic, colicky abdominal pain since last three months. Abdominal pain was accompanied by distension of the lower abdomen. No significant history of drug intake/medication by mother during pregnancy or congenital anomalies in family was elicited. On local examination external genitalia were normal.

Per-speculum examination showed small opening $2 \mathrm{~cm}$ from urethra. On per rectal 
examination cervix and uterus were felt, right adnexa was free and mass was felt in left adnexa extending upto midline, which was firm in consistency. On ultrasound (US) the uterus and cervix appeared to be distended with fluid suggesting hematometra and hematocolpos. Both ovaries were seen. Bilateral kidneys and ureters and bladder were normal. Patient was advised Magnetic Resonance Imaging (MRI) for further evaluation. MRI pelvis was done with and without ultrasound jelly in introitus. The jelly serves as contrast and better delineates the septum. MRI pelvis shows a low transverse vaginal septum resulting into hematometra, hematocolpos and bilateral hematosalpinx. The distance between the lower end of the vagina and the introitus was $15 \mathrm{~mm}$. Thickness of the septum was two $\mathrm{mm}$.

A vaginoplasty was being planned, but there was a spontaneous rupture of the septum. The ruptured contents were tarry and foul smelling. A post-rupture follow up MRI was also done in which the hematometra and hematocolpos were partially relieved but hematosalpinx was persistent. After spontaneous rupture, patient was started on progesterone. A thorough vaginal examination was done under general anaesthesia which showed ruptured septum, hence a definitive resection and vaginoplasty ( $Z$ plasty) was planned and performed at a later date. A vaginal mould of two $\mathrm{cm}$ diameter and four $\mathrm{cm}$ length was placed in the vagina to maintain patency and improve functional capability.

\section{Discussion}

In complete vaginal septum, the menstrual blood accumulates resulting in hematocolpos and hematometra, rarely hematosalpinx may result. These patients usually present at adolescence with cyclic lower abdominal pain and occasionally with a lower abdominal mass (hematometra). An incomplete septum allows partial flow of

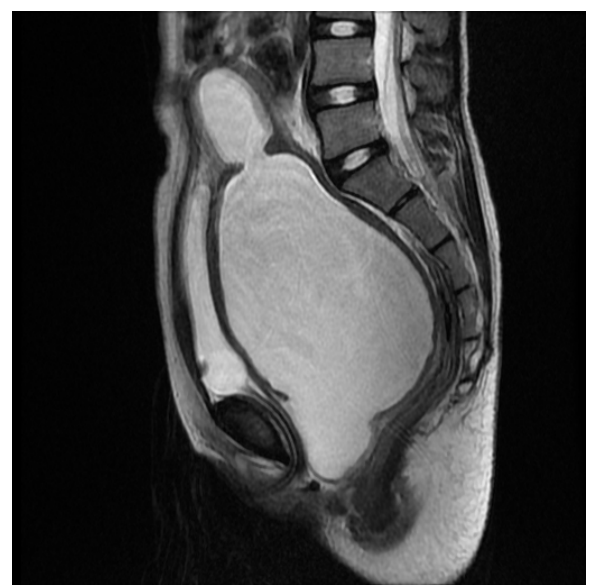

Fig.1: Sagittal T2WI showing complete low transverse vaginal septum resulting in hematometra and hematocolpos.

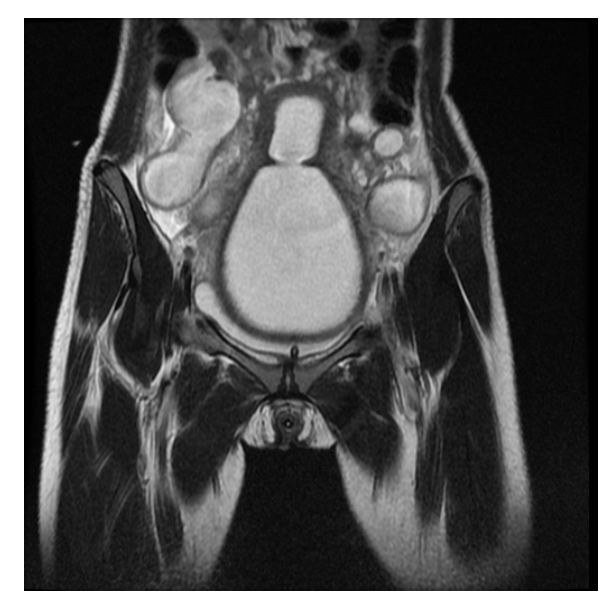

Fig.2: Coronal T2WI also shows bilateral hematosalpinx along with hematometra and hematocolpos.

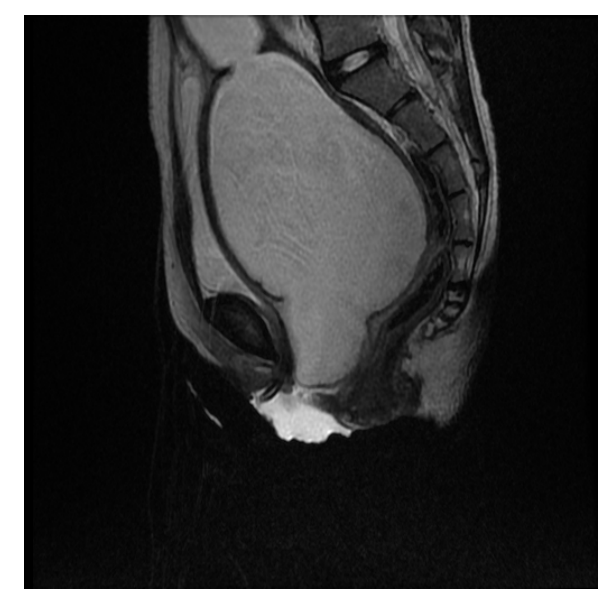

Fig.3: Sagittal T2WI after inserting jelly in introitus. The low transverse vaginal septum is clearly visualized and thickness can be accurately measured. 
menstrual blood, and these patients present with dysmenorrhea, hypo-menorrhea, dyspareunia and foul-smelling vaginal discharge. As per the classification of vaginal anomalies by American Society of Reproductive Medicine, transverse vaginal septum is class I which says transverse vaginal septum is a vertical fusion defect of the Mullerian ducts that develops due to failure of resorption of the tissue between the vaginal plate and the caudal aspect of the fused Mullerian ducts. Normally this resorption occurs around the $5^{\text {th }}$ month of gestation. A transverse vaginal septum results into two segments of vagina, reducing its functional length and cause outlet tract obstruction in most cases [4].

Patients often present at menarche with cyclic pelvic pain and primary amenorrhea due to obstructed menses. Incomplete (perforated) septum may manifest even later, with dyspareunia and dysmenorrhea $[5,6]$. Patients with imperforate transverse vaginal septum generally have a normal upper genital tract and therefore do not have reduced fertility.

In our case hematometra and hematocolpos were seen on ultrasound however hematosalpinx and the exact location and thickness of septum were not satisfactorily seen, hence an MRI was done. MRI revealed a well-defined $2 \mathrm{~mm}$ thick septum. The septum was exceptionally well demarcated on T2 weighted images due to the use of ultrasound jelly. The septum is seen as a hypo-intense band of tissue in between the hyper-intense collection internally and ultrasound jelly externally. MR imaging was also useful in depicting the pelvic anatomy further aiding in the selection of the appropriate management [7]. Management depends on the thickness and position of the septum [8].

Transverse vaginal septum adversely affects the fertility and obstetric outcomes in the patient, however early an intervention can lead to a better outcome. Ultrasound helps in localization and characterization of the lesion but MRI is important in confirming the vaginal septum and its related complications more accurately than any other imaging modality and helps in deciding the management and so as predicting future outcome. Introduction of ultrasound jelly in the vagina/introitus for better delineation of the septum seems promising. This is especially useful when the septum is very thin.

\section{Conclusion}

Whenever a female in the pre-menarchal age presents to the emergency department with history of episodic, colicky abdominal pain with distension of the lower abdomen a possibility of transverse vaginal septum should always be borne in mind.

Contributors: CR: manuscript writing, literature review; $\mathrm{NG}$, $\mathrm{AD}$, VB: manuscript editing, literature review; $\mathrm{AB}$ : critical inputs into the manuscript, and patient management. NG will act as guarantor. All authors approved the final version of this manuscript.

Funding: None; Competing interests: None stated.

\section{References}

1. Caloia DV, Morris H, Rahmani MR. Congenital transverse vaginal septum: vaginal hydrosonographic diagnosis. Journal of Ultrasound in Medicine, 1998;17:261-264.

2. Delaunay. Etude sur le cloisonnement transversal du vagin complet et incomplete d'origine congenital, Thesis, Paris 1877.

3. Rock JA, Lesley LB. Surgery for anomalies of the mullerian ducts. In: Rock JA, Jones HW, Te Linde RWTLsog, eds. Te Linde's Operative Gynecology. $10^{\text {th }}$ ed. Philadelphia, London: Lippincott Williams and Wilkins; 2008. pp. 539-584.

4. Junqueira BL, Allen LM, Spitzer RF, Lucco KL, Babyn PS, Doria AS. Müllerian duct anomalies and mimics in children and adolescents: Correlative intraoperative assessment with clinical imaging. RadioGraphics, 2009;29:1085-1103.

5. Laufer MR, Goldstein DP, Hendren WH. Structural abnormalities of the female reproductive tract. In: Emans SJ, Laufer MR, Goldstein DP, eds. Pediatric and adolescent gynecology. $5^{\text {th }}$ ed. Boston, Mass: Lippincott Williams \& Wilkins, 2005; 362-416. 
6. Edmonds DK. Rokitansky syndrome and other Mullerian anomalies. In: Balen AH, Creighton SM, Davies MC, MacDougall J, Stanhope R, eds. Paediatric and adolescent gynaecology. Cambridge, England: Cambridge University Press, 2004;267-274.
7. Lopez C, Balogun M, Ganesan R, Olliff JF. MRI of vaginal conditions. Clin Radiol. 2005;60:648-662.

8. Burgis J. Obstructive Müllerian anomalies: case report, diagnosis, and management. Am J Obstet Gynecol. 2001;185:338-344. 